\title{
Diffusion-reaction model for the internal sulfate attack in concrete
}

\author{
A. Campos ${ }^{\mathrm{a}, *}$, C.M. López ${ }^{\mathrm{b}}$, A. Aguado ${ }^{\mathrm{c}}$ \\ ${ }^{a}$ Dept. of Structures, Urban Planning and Technology Center, Londrina State University, Londrina, Brazil \\ ${ }^{\mathrm{b}}$ Dept. of Geotechnical Engineering and Geo-Sciences, Barcelona School of Civil Engineering, UPC-BarcelonaTech, Spain \\ ${ }^{\mathrm{C}}$ Dept. of Construction Engineering, Barcelona School of Civil Engineering, UPC-BarcelonaTech, Spain
}

\section{H I G H L I G H T S}

- A diffusion-reaction model is developed for the internal sulfate attack (ISA).

- The ISA is caused by the oxidation of the pyrrhotite into the aggregates.

- The model can predict the distribution and evolution of the volumetric deformations.

- The proposed model was applied in two real dams.

\section{A R T I C L E I N F O}

\section{Article history:}

Received 25 April 2015

Received in revised form 9 October 2015

Accepted 28 October 2015

Available online $\mathrm{xxxx}$

\section{Keywords:}

Sulfate attack

Expansion

Concrete

Kinetics and diffusion

Dams

\begin{abstract}
A B S T R A C T
In the analysis of the behavior of concrete structures affected by expansive problems, it is often necessary to use kinetics models of the reactions involved to assess and predict the magnitude, distribution, and evolution over the time of expansion. In this study, a diffusion-reaction model is developed for the internal sulfate attack (ISA) problem due to the oxidation of the pyrrhotite into the aggregates. The model takes into account the kinetics of the pyrrhotite oxidation under the two main oxidizers and the oxygen transport in the concrete. The dependence of the water content of the concrete is included in the analysis, which affects the reaction kinetics and oxygen diffusion. The developed model is applied to two real dams affected by the ISA. The results obtained validate the model and demonstrate its potential for evaluating and predicting the behavior of structures affected by the ISA.
\end{abstract}

(c) 2015 Published by Elsevier Ltd.

\section{Introduction}

Degradation of concrete due to the presence of iron sulfides (such as pyrite and pyrrhotite) in the aggregates is being widely studied in recent years. These sulfides, in the presence of water and oxygen, are oxidized releasing compounds, which can cause a sulfate attack in concrete, called internal sulfate attack (ISA) [1-8].

The sulfate attack is caused by the reaction of sulfate ions with the cement hydration products. The attack mechanism involves several chemical reactions that may produce secondary products such as ettringite, gypsum, and thaumasite [9-13]. An expansion is the result of the formation of these products, which can cause cracking that, in extreme cases, may lead to the disintegration of the mortar or the concrete [14-16].

\footnotetext{
* Corresponding author.

E-mail addresses: andre.moura@uel.br (A.Campos), carlos.maria.lopez@upc.edu (C.M. López), antonio.aguado@upc.edu (A. Aguado).
}

This type of concrete expansion has been detected in the dam of Rio Descoberto (Brazil) [17] and some Spanish dams such as Graus, Tavàscan, Torán, Rumedo, and Paso Nuevo. The structural implications of the ISA depend of the structure type, characteristics of the cement and aggregates used, as well the environmental conditions.

For a proper evaluation of the impact of such a degradation on the structure, it is necessary to determine the distribution of the expansions inside the structures and the deformations evolution over time. This is usually a difficult task, and the deformations are commonly estimated using phenomenological criteria based on approximations and simplifying assumptions.

Considerable efforts have been made in the development of kinetic models of expansive processes in recent years, especially applied to other types of expansion, more studied in the literature, as the alkali aggregate reaction (AAR) $[18,19]$ and the external sulfate attack (ESA) [20-25]. These models are based on physical and chemical processes, such as transport of reactants and the kinetic of the chemical reactions. This approach allows a direct and consistent determination of the evolution in time, distribution, and generated deformations. This information is very important for the 
study and prediction of future behavior of the affected structures, and to support decisions regarding actions against the problem.

The main objective of this study is to propose a kinetic model to predict the evolution in time and distribution of the ISA in the concrete, considering the two oxidants of the pyrrhotite as well as the effect of the environmental conditions. To do this, a reaction-diffusion model is developed, which takes into account the oxygen transport into the concrete and its consumption on the oxidation reactions. The results of the application of this model are compared with data in the literature and are validated with the measured displacements in two real dams affected by the ISA.

\section{Background of the diffusion-reaction models}

In general, the simulation of chemical reactions requires the consideration of the transport processes involved. The transport of chemical compounds in porous materials is generally considered as a diffusion process, which can be described by Fick's law [26].

A diffusion-reaction system is obtained by the consideration of the transport process with the chemical reactions. Mathematical models are formulated to address this analysis to determine the variation of the concentration of one or more compounds in time under the influence of two processes: the chemical reactions, which transform the substances locally and the transport (by diffusion) of these substances in space [27].

Diffusion-reaction models have been used to study various physical and chemical processes in concrete, such as carbonation $[28,29]$, expansive phenomena such as ASR [18,19,30] and the ESA [20,21], among others. The solution of these models generally involves a system of partial differential equations that must be solved simultaneously for the chemical analysis and transport problem [31,32].

In the study of the ISA by pyrrhotite oxidation in the aggregates, the oxidation reactions mainly depend on the oxygen transport from the outside to inside of the concrete.

\section{Kinetic model for pyrrhotite oxidation in the concrete}

For the development of the kinetic model, first, a review of the chemical reactions involved was carried out, and then a diffusionreaction model of oxygen in the concrete was proposed by taking into account the two main oxidizers of pyrrhotite.

\subsection{Pyrrhotite oxidation}

The pyrrhotite is oxidized when exposed to oxygen and in the presence of water, leading to the formation of sulfates and iron hydroxides, and causing a decrease in the alkalinity of the system [33]. Oxidation of these sulfides can be initiated by the atmospheric oxygen or iron ions [34].

The following four chemical reactions govern the oxidation process of pyrrhotite by the two oxidation modes mentioned earlier (with $x$ ranging between 0 and 0.125 ):

$$
\begin{aligned}
& \mathrm{Fe}_{1-x} \mathrm{~S}+\left(2-\frac{x}{2}\right) \mathrm{O}_{2}+x \mathrm{H}_{2} \mathrm{O} \rightarrow(1-x) \mathrm{Fe}^{2+}+2 x \mathrm{H}^{+}+\mathrm{SO}_{4}^{2-} \\
& \mathrm{Fe}^{2+}+\frac{1}{4} \mathrm{O}_{2}+\mathrm{H}^{+} \rightarrow \mathrm{Fe}^{3+}+\frac{1}{2} \mathrm{H}_{2} \mathrm{O} \\
& \mathrm{Fe}^{3+}+3 \mathrm{H}_{2} \mathrm{O} \rightarrow \mathrm{Fe}(\mathrm{OH})_{3(\mathrm{~s})}+3 \mathrm{H}^{+}
\end{aligned}
$$

$\mathrm{Fe}_{1-x} \mathrm{~S}+(8-2 x) \mathrm{Fe}^{3+}+4 \mathrm{H}_{2} \mathrm{O} \rightarrow(9-3 x) \mathrm{Fe}^{2+}+8 \mathrm{H}^{+}+\mathrm{SO}_{4}^{2-}$
In the case of oxygen as the main oxidant, reactions (1) and (2) govern process followed by Eq. (3). This occurs at a pH above 4 [34]. Reaction (1) produces sulfuric acid and $\mathrm{Fe}^{2+}$ ions, which are converted into $\mathrm{Fe}^{3+}$ ions by reaction (2), and then into iron hydroxide (which is solid) by reaction (3). This process can also be represented by a single overall reaction (5), obtained as a result of the sum of reactions (1)-(3).

$$
\begin{gathered}
\mathrm{Fe}_{1-x} \mathrm{~S}+\left(\frac{9-3 x}{4}\right) \mathrm{O}_{2}+\left(\frac{5-3 x}{2}\right) \mathrm{H}_{2} \mathrm{O} \\
\rightarrow(1-x) \mathrm{Fe}(\mathrm{OH})_{3(\mathrm{~s})}+2 \mathrm{H}^{+}+\mathrm{SO}_{4}^{2-}
\end{gathered}
$$

In the case of $\mathrm{Fe}^{3+}$ ion as the main oxidant, reactions (2) and (4) govern the process. This occurs at a $\mathrm{pH}$ lower than 4 [35]. These two reactions occur maintaining a cycle. While reaction (4) consumes $\mathrm{Fe}^{3+}$ and produces a greater extent of $\mathrm{Fe}^{2+}$, reaction (2) consumes $\mathrm{Fe}^{2+}$ and produces $\mathrm{Fe}^{3+}$, which continues oxidizing the pyrrhotite by reaction (4). This process requires an initial amount of $\mathrm{Fe}^{3+}$ or $\mathrm{Fe}^{2+}$ to start, in addition to the oxygen in reaction (2).

Both the oxidation processes consume oxygen (Expressions (1) and (2)) and either of them can occur depending on the $\mathrm{pH}$. In this regard, it is well known that the cement paste present in the concrete tends to have highly alkaline $\mathrm{pH}$, although the $\mathrm{pH}$ that will define the main oxidizer will not be the $\mathrm{pH}$ of the cement paste, but the $\mathrm{pH}$ of the aqueous solution in the zone in which oxidation occurs, which, for the case studied, is the aggregate. The oxidation process produces tends to reduce the $\mathrm{pH}$. As a result, an alkaline zone can be converted into acid zone, changing the main oxidizer.

\subsection{Diffusion-reactions equations and reaction kinetics}

Expression (6) is obtained by applying Fick's Law. This equation allows taking into account the process of transport of oxygen from an external source (the atmospheric air) and its consumption by the chemical reactions inside the concrete.

$$
\frac{\left[\mathrm{O}_{2}\right]}{t}=\nabla^{2}\left(D\left[\mathrm{O}_{2}\right]\right)-\frac{\left[\mathrm{O}_{2}\right]_{r i}}{t}
$$

where $D\left(\mathrm{~m}^{2} / \mathrm{s}\right)$ is the diffusion coefficient of the oxygen in the concrete, $[i]$ denotes the concentration of compound $i$, and $\frac{\left[\mathrm{O}_{2} l_{\text {ri }}\right.}{t}$ is the consumption of the oxygen by the reaction $i$.

The kinetics of a chemical reaction can be expressed using a law where the reaction rate is obtained as a function of the concentration of reactants and a kinetic coefficient $(k)$ characteristic of each reaction [36]. For example in a generic reaction $A+B \rightarrow C$ the rate equation can be written as: $\partial[\mathrm{A}] / \partial t=-k[\mathrm{~A}]^{n}[\mathrm{~B}]^{m}$, where $n$ and $m$ are the partial orders of the reaction (determined empirically). Based on the few available experimental data, the parameters $k$, $n$ and $m$ cannot be suitably determined for all involved reactions. For these reason first-order kinetics laws (with $n=m=1$ ) were adopted, remaining only the parameter $k$ to determine for each reaction.

\subsubsection{Oxygen as main oxidant}

Reactions (1)-(3) occur when the $\mathrm{pH}$ in the zone in which the oxidation occurs is greater than 4 . For this case, reaction (5) can be used to describe the overall kinetics. This allows obtaining expressions (7) and (8).

$$
\begin{aligned}
& \frac{\left[\mathrm{O}_{2}\right]}{t}=\nabla^{2}\left(D\left[\mathrm{O}_{2}\right]\right)-q k_{5}\left[\mathrm{O}_{2}\right]\left[\mathrm{Fe}_{1-x} \mathrm{~S}\right] \\
& \frac{\left[\mathrm{Fe}_{1-x} \mathrm{~S}\right]_{r 5}}{t}=-k_{5}\left[\mathrm{O}_{2}\right]\left[\mathrm{Fe}_{1-x} \mathrm{~S}\right]
\end{aligned}
$$


where $q=(9-3 x) / 4$ is the stoichiometric coefficient, which accompanies $\mathrm{O}_{2}$ in reaction (5) and $k_{5}$ is the kinetic coefficient of reaction (5).

Expression (7) is the diffusion-reaction equation of oxygen, where the term that expresses the oxygen consumption in expression (6) is replaced by the kinetics equation of reaction (5) (in terms of the oxygen consumption). Expression (8) is the kinetics equation of reaction (5) in terms of pyrrhotite consumption.

The concentration of pyrrhotite and oxygen at any point of the volume of concrete for a given time is given by the solution of the system of equations composed of expressions (7) and (8). This system can be solved numerically by an incremental and iterative process, where the oxygen concentration is a global variable (field variable) of the problem, while the iron sulfide concentration is a local variable.

\subsection{2. $\mathrm{Fe}^{3+}$ ion as main oxidant}

The cycle between reactions (2) and (4) takes places when the $\mathrm{pH}$ in the zone in which the oxidation occurs is lower than 4 . Expressions (9)-(12) are obtained in the same way as in the previous section.

$\frac{\left[\mathrm{O}_{2}\right]}{t}=\nabla^{2}\left(D\left[\mathrm{O}_{2}\right]\right)-g k_{2}\left[\mathrm{O}_{2}\right]\left[\mathrm{Fe}^{2+}\right]$

$\frac{\left[\mathrm{Fe}_{1-\chi} \mathrm{S}\right]_{r 4}}{t}=-k_{4}\left[\mathrm{Fe}_{1-x} \mathrm{~S}\right]\left[\mathrm{Fe}^{3+}\right]$

$\frac{\left[\mathrm{Fe}^{2+}\right]}{t}=\delta k_{4}\left[\mathrm{Fe}_{1-x} \mathrm{~S}\right]\left[\mathrm{Fe}^{3+}\right]-k_{2}\left[\mathrm{O}_{2}\right]\left[\mathrm{Fe}^{2+}\right]$

$\frac{\left[\mathrm{Fe}^{3+}\right]}{t}=k_{2}\left[\mathrm{O}_{2}\right]\left[\mathrm{Fe}^{2+}\right]-\rho k_{4}\left[\mathrm{Fe}_{1-x} \mathrm{~S}\right]\left[\mathrm{Fe}^{3+}\right]$

where $k_{2}$ and $k_{4}$ are the kinetics coefficients of reactions (2) and (4), respectively, and $g=1 / 4, \delta=9-3 x$, and $\rho=8-2 x$ are the stoichiometric coefficients, which accompany the $\mathrm{O}_{2}$ in reaction (2), $\mathrm{Fe}^{2+}$, and $\mathrm{Fe}^{3+}$ in reaction (4), respectively.

The diffusion of the $\mathrm{Fe}^{2+}$ and $\mathrm{Fe}^{3+}$ will not be taken into account, because the proposed model considers the concrete as a homogeneous material, and the diffusion of the iron ions occur between aggregates and the mortar (process that could only be taken into account in a heterogeneous model like, for example, a mesostructural model).

Expression (9) is the diffusion-reaction equation of oxygen, where the term that expresses the oxygen consumption in expression (6) is replaced by the kinetics equation of reaction (2) (in terms of the oxygen consumption). Expression (10) is the kinetics equation of reaction (4) in terms of pyrrhotite consumption. Expression (11) is the continuity equation of the $\mathrm{Fe}^{2+}$ ion concentration in time, equal to that produced by reaction (4) $\left(\partial\left[\mathrm{Fe}^{2+}\right]_{r 4} / \partial\right.$ $\left.t=\delta k_{4}\left[\mathrm{Fe}_{1-x} \mathrm{~S}\right]\left[\mathrm{Fe}^{3+}\right]\right)$ and less than that consumed by reaction (2) $\left(\partial\left[\mathrm{Fe}^{2+}\right]_{r 2} / \partial t=-k_{2}\left[\mathrm{O}_{2}\right]\left[\mathrm{Fe}^{2+}\right]\right)$. Likewise, expression (12) is the continuity equation of the concentration of $\mathrm{Fe}^{3+}$ ions, equal to that produced by reaction $(2)\left(\partial\left[\mathrm{Fe}^{3+}\right]_{r 2} / \partial t=k_{2}\left[\mathrm{O}_{2}\right]\left[\mathrm{Fe}^{2+}\right]\right)$ and less than that consumed by reaction $(4)\left(\partial\left[\mathrm{Fe}^{3+}\right]_{r 4} / \partial t=-\rho k_{4}\left[\mathrm{Fe}_{1-x} \mathrm{~S}\right]\left[\mathrm{Fe}^{3+}\right]\right)$.

The concentrations of pyrrhotite, oxygen, $\mathrm{Fe}^{2+}$, and $\mathrm{Fe}^{3+}$ at any point of the volume of concrete for a given time are given by the solution of the system of equations composed of expressions (9)(12). Similar to the previous case, this system can be solved numerically by an incremental and iterative process, where the oxygen concentration is a global variable (field variable) of the problem, while the concentrations of pyrrhotite, $\mathrm{Fe}^{2+}$, and $\mathrm{Fe}^{3+}$ are local variables.

\section{Sulfate attack}

The sulfuric acid produced by pyrrhotite oxidation in the aggregates when in contact with the cement paste starts an acid attack. Evidences of this type of attack have been observed in concrete core samples of some dams such as Graus and Tavàscan (in which the aggregates used contain pyrrhotite). In these core samples, it has been found that the $\mathrm{pH}$ in the environment of the aggregates is lower than most of the cement paste, which shows that the acid attack originated from the aggregates [37].

The most important chemical reactions involved have been widely studied in the case of external sulfate attack [14-16,21]. The sulfuric acid moves by diffusion from the interior of the aggregate to the cement paste, initiating the sulfate attack. Gypsum $\left(\mathrm{CaSO}_{4} \cdot 2 \mathrm{H}_{2} \mathrm{O}\right)$ is the primary product of this attack, resulting from the reaction of sulfuric acid with calcium hydroxide (portlandite) of the cement paste. This gypsum may react with the different phases of nondiffusive calcium aluminates present in the hydrated cement paste, forming secondary ettringite $\left(3 \mathrm{CaO} \cdot \mathrm{Al}_{2} \mathrm{O}_{3} \cdot 3 \mathrm{CaSO}_{4} \cdot 32 \mathrm{H}_{2} \mathrm{O}\right.$ ). The following expressions are the reactions of the gypsum with unreacted tricalcium aluminate (13), monosulfoaluminate (14), and calcium aluminate hydrate (15), forming secondary ettringite.

$$
\begin{gathered}
3 \mathrm{CaO} \cdot \mathrm{Al}_{2} \mathrm{O}_{3}+3\left(\mathrm{CaSO}_{4} \cdot 2 \mathrm{H}_{2} \mathrm{O}\right)+26 \mathrm{H}_{2} \mathrm{O} \\
\rightarrow 3 \mathrm{CaO} \cdot \mathrm{Al}_{2} \mathrm{O}_{3} \cdot 3 \mathrm{CaSO}_{4} \cdot 32 \mathrm{H}_{2} \mathrm{O}
\end{gathered}
$$

$3 \mathrm{CaO} \cdot \mathrm{Al}_{2} \mathrm{O}_{3} \cdot \mathrm{CaSO}_{4} \cdot 12 \mathrm{H}_{2} \mathrm{O}+2\left(\mathrm{CaSO}_{4} \cdot 2 \mathrm{H}_{2} \mathrm{O}\right)+16 \mathrm{H}_{2} \mathrm{O}$

$$
\rightarrow 3 \mathrm{CaO} \cdot \mathrm{Al}_{2} \mathrm{O}_{3} \cdot 3 \mathrm{CaSO}_{4} \cdot 32 \mathrm{H}_{2} \mathrm{O}
$$

$4 \mathrm{CaO} \cdot \mathrm{Al}_{2} \mathrm{O}_{3} \cdot 13 \mathrm{H}_{2} \mathrm{O}+3\left(\mathrm{CaSO}_{4} \cdot 2 \mathrm{H}_{2} \mathrm{O}\right)+14 \mathrm{H}_{2} \mathrm{O}$

$$
\rightarrow 3 \mathrm{CaO} \cdot \mathrm{Al}_{2} \mathrm{O}_{3} \cdot 3 \mathrm{CaSO}_{4} \cdot 32 \mathrm{H}_{2} \mathrm{O}+\mathrm{CaO} \cdot \mathrm{H}_{2} \mathrm{O}
$$

\section{Global kinetics: oxidation + sulfate attack}

This section discusses how to consider the oxidation process and sulfate attack together. Fig. 1 shows a schematic of the oxidation of a vein (or band) of iron sulfide in an aggregate immersed in the cement paste. The red ${ }^{1}$ outline around the iron sulfide is the zone in which the oxidation occurs, releasing excess sulfuric acid and iron ions by diffusion toward the cement paste. The white outline around the aggregate is the area in which the sulfuric acid in contact with the compounds of the cement paste reacts forming gypsum and then secondary ettringite.

At a $\mathrm{pH}$ higher than 4 , iron ions $\left(\mathrm{Fe}^{2+}\right.$ and $\left.\mathrm{Fe}^{3+}\right)$ precipitate, forming iron hydroxide (potentially expansive) [35]. In the case of oxidation by $\mathrm{O}_{2}$, the iron hydroxide formation would be in the same zone where oxidation occurs (red outline in Fig. 1), because in this zone, the $\mathrm{pH}$ is higher than 4 . In the case of oxidation by $\mathrm{Fe}^{3+}$, as the environment of oxidation is highly acid $(\mathrm{pH}<4)$, iron hydroxide is formed when surplus $\mathrm{Fe}^{3+}$ ions of oxidation are transported by diffusion from the inside of the aggregate to the cement paste, finding a less acid zone $(\mathrm{pH}>4$, at some point between the red and white outline illustrated in Fig. 1).

Some authors have also noted the formation of hydrated iron sulfide that is potentially expansive [37]. The present study takes into account only the formation of iron hydroxide, which is most commonly reported in the literature $[34,35,38]$.

Ettringite formation depends on a sulfate transport process from the inside of the aggregates to the cement paste at a distance of the order of centimeters (as illustrated in Fig. 1). This process is

${ }^{1}$ For interpretation of color in Fig. 1, the reader is referred to the web version of this article. 


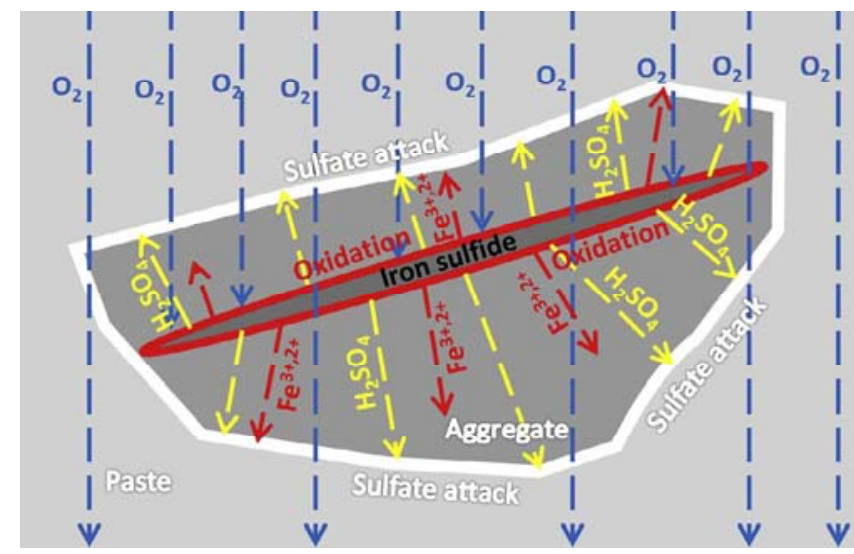

Fig. 1. Schematic of the oxidation of a vein (or band) of iron sulfide in an aggregate immersed in the cement paste.

much faster than the oxidation of pyrrhotite, which depends on the diffusion of oxygen into the concrete at a distance of the order of meters in case of dams.

For these reasons, from a practical standpoint, the sulfate attack from the aggregates can be considered instantaneous, when compared with the oxidation of pyrrhotite. Thereby, an additional kinetic treatment is not necessary.

\section{Determination of volumetric expansion}

The evolution of volumetric expansion $(\Delta V / V)_{(t)}$ over time can be expressed as the function of pyrrhotite oxidation, as follows:

$\left(\frac{V}{V}\right)_{(t)}=\left(\frac{V}{V}\right)_{\infty} \cdot\left(\frac{\left[\mathrm{Fe}_{1-\chi} \mathrm{S}\right]_{(0)}-\left[\mathrm{Fe}_{1-\chi} \mathrm{S}\right]_{(t)}}{\left[\mathrm{Fe}_{1-\chi} \mathrm{S}\right]_{(0)}}\right)$

where $(\Delta V / V)_{\infty}$ is the final volumetric expansion (or maximum expansion) and $\left[\mathrm{Fe}_{1-\chi} \mathrm{S}\right]_{(0)}$ and $\left[\mathrm{Fe}_{1-\chi} \mathrm{S}\right]_{(t)}$ are the initial pyrrhotite concentration and in the time $t$, respectively. The value of $\left[\mathrm{Fe}_{1-x} \mathrm{~S}\right]_{C^{-}}$ t) is obtained by solving the system of equations composed of expressions (7) and (8) or expressions (9)-(12), depending on the main oxidant.

Determination of the expansion has been addressed in the literature in two different ways: in a phenomenological way, where the deformation is obtained as necessary to fit the measured displacements in real structures or core samples in the laboratory, or using an analytical model where the deformation is obtained as a function of the amount of expansive products formed.

A possible analytical approach consists of obtaining the volumetric expansion as the difference between the volumes of products and reactants $[20,21,39]$. This requires knowing the molar volume $(m)$ of the compounds involved in the reactions. Table 1 presents the molar volume of the compounds involved in the ISA.

For the ISA, the volumetric deformation of the concrete $(\Delta V / V)_{\text {total }}$ is obtained as the sum of the deformation due to the formation of iron hydroxide and ettringite, as expressed in the following expression:

$\left(\frac{V}{V}\right)_{\text {total }}=\left(\frac{V}{V}\right)_{\mathrm{Fe}(\mathrm{OH})_{3}}+\left(\frac{V}{V}\right)_{\text {ettringite }}$

The volumetric deformation due to the formation of iron hydroxide is obtained as a function of pyrrhotite concentration and the molar volume $(m)$ of $\mathrm{Fe}(\mathrm{OH})_{3}$ and $\mathrm{Fe}_{1-x} \mathrm{~S}$ :

$\left(\frac{V}{V}\right)_{\mathrm{Fe}(\mathrm{OH})_{3}}=\left[\mathrm{Fe}_{1-x} \mathrm{~S}\right]\left\{(1-x) m_{\mathrm{Fe}(\mathrm{OH})_{3}}-m_{\mathrm{Fe}_{1-x} \mathrm{~S}}\right\}$
Table 1

Molar volumes of the compounds involved in the ISA [40-42].

\begin{tabular}{|c|c|c|}
\hline Compound & Name & $m\left(\mathrm{~cm}^{3} / \mathrm{mol}\right)$ \\
\hline $3 \mathrm{CaO} \cdot \mathrm{Al}_{2} \mathrm{O}_{3}$ & Tricalcium aluminate & 88.8 \\
\hline $3 \mathrm{CaO} \cdot \mathrm{Al}_{2} \mathrm{O}_{3} \cdot \mathrm{CaSO}_{4} \cdot 12 \mathrm{H}_{2} \mathrm{O}$ & Monosulfoaluminate & 313.0 \\
\hline $4 \mathrm{CaO} \cdot \mathrm{Al}_{2} \mathrm{O}_{3} \cdot 13 \mathrm{H}_{2} \mathrm{O}$ & Calcium aluminate hydrate & 276.2 \\
\hline $3 \mathrm{CaO} \cdot \mathrm{Al}_{2} \mathrm{O}_{3} \cdot 3 \mathrm{CaSO}_{4} \cdot 32 \mathrm{H}_{2} \mathrm{O}$ & Ettringite & 725.1 \\
\hline $\mathrm{CaSO}_{4} \cdot 2 \mathrm{H}_{2} \mathrm{O}$ & Gypsum & 74.2 \\
\hline $\mathrm{Ca}(\mathrm{OH})_{2}$ & Calcium hydroxide & 33.1 \\
\hline $\mathrm{H}_{2} \mathrm{O}$ & Water & 18.0 \\
\hline $\mathrm{Fe}(\mathrm{OH})_{3}$ & Iron hydroxide & 26.99 \\
\hline $\mathrm{Fe}_{1-x} \mathrm{~S}$ to $x=0,125$ & Iron sulfide & 17.58 \\
\hline
\end{tabular}

The volumetric deformation due to ettringite formation is obtained from the sum of the volumetric deformation generated by reactions (13)-(15), depending on the concentration of the aluminate compound in each reaction, as shown in Eq. (19):

$$
\left(\frac{V}{V}\right)_{\text {ettringite }}=\sum_{i=1}^{3}\left[\mathrm{CA}_{i}\right]\left\{m_{\mathrm{CA}_{i}}+w_{i} m_{\text {meso }}-m_{\text {ettringite }}\right\}
$$

where $\left[\mathrm{CA}_{i}\right]$ is the aluminate compound concentration in the reaction $i, w_{i}$ is the stoichiometric coefficient accompanying the gypsum in the reaction $i$, and $i$ (from 1 to 3 ) denotes the reaction ((13), (14), or (15), respectively).

The volumetric deformation determined using expression (17) does not express the real deformation present in the concrete. This occurs because part of the expansive products will fill voids reducing the final expansion. One way to take this into account was given by Tixier and Mobasher [21], who considered the void volume that can be filled with expansive products corresponding to a fraction of concrete porosity $(\phi)$, defined as the fraction of capillary porosity $(f)$. Thus, the final deformation can be calculated as:

$\left(\frac{V}{V}\right)_{\infty}=\left(\frac{V}{V}\right)_{\text {total }}-f \cdot \phi$

The parameter $f$ is a common and useful way to represent the filling of a part of the voids in concrete by the reactions products $[20,21]$, but has great variability in the literature, ranging from 0.05 to 0.45 [21]. The dispersion of these values suggests that this choice may be rather arbitrary and for this reason this is a questionable parameter since it would cause a wide variation of the final volumetric expansion calculated by expression (20). However, this parameter represents an important process and must be considered in the model.

\section{Influence of environmental conditions on model parameters}

The water content of the concrete and the temperature can affect the kinetic coefficients of the reactions and the diffusion coefficient of oxygen.

The presence of water is an essential factor for the development of the oxidation reactions inside the concrete. In case of low water content in the environment of the pyrrhotite particles, oxidation will not occur. However, increasing the water content increases the number of pyrrhotite particles in contact with water, presenting conditions for the development of oxidation. Thus, the water content is related to the amount of sulfides oxidized per unit of time (the speed of the oxidation process).

An indirect way is proposed to take into account the effect of water content $(\theta)$ on the kinetics of the oxidation, relating the kinetic coefficients (parameter that directly affects the kinetics of the reaction) to the water content on the concrete through expression (21)

$k_{i(\theta)}=k_{i(1)}\left[\frac{\theta e^{\beta}}{1+\theta\left(e^{\beta}-1\right)}\right]$ 
where $k_{i(1)}$ is the kinetics coefficient of the reaction $i$ in the saturated concrete and $\beta$ is a parameter that controls the shape of the curve, allowing to obtain variations between the kinetic and water content with different curvatures, depending on the value and sign of the coefficient $\beta$, as show in Fig. 2 .

The most reasonable values of $\beta$ are those that allow obtaining kinetic coefficients with more significant values for high water contents (negative values of $\beta$ ), because the amount of water is necessary not only for the reactions but also for the reactants to remain in aqueous solution.

The diffusion coefficient of oxygen is another parameter strongly dependent on the water content of the concrete. Experimental studies have shown that this coefficient is maximum in a dry concrete, leading to a very low value (near to zero) in saturated concrete [43-45]. To take this effect into account, expression (22) is proposed:

$D_{(\theta)}=D_{(0)}\left[1-\frac{\theta e^{\gamma}}{1+\theta\left(e^{\gamma}-1\right)}\right]$

where $D_{(0)}$ is the diffusion coefficient of oxygen in a dry concrete and $\gamma$ is a parameter that controls the shape of the curve.

In Fig. 3, the continuous line shows the experimental value of the diffusion coefficient of oxygen in the concrete obtained for $w / c=0.67$ [44], while the discontinuous line shows the one calculated with expression (22) with $\gamma=0.3$, which matches very well with the experimental curve. In case of a dry concrete $(\theta=0 \%)$, the value of the diffusion coefficient is $10^{-7} \mathrm{~m}^{2} / \mathrm{s}$, and for a saturated concrete $(\theta=100 \%)$, the diffusion coefficient tends to zero (impermeable to oxygen)

As shown, in a dry concrete there is no water, but good diffusion of oxygen, and in a water-saturated concrete there is plenty of water but no oxygen diffusion. So, the ideal conditions for the oxidation reaction will happen in an intermediated value of water content, not too dry and not too saturated.

The overall chemical reaction kinetics are affected by temperature. This effect can be taken into account in the kinetic coefficient using the Arrhenius equation. Due to the lack of experimental data, the estimation of this equation parameter (the pre-exponential constant and the activation energy of the reactions) is a difficult task.

The effect of temperature in the kinetics coefficients must be considered in structures that present significant temperature variations. This effect should also be taken into account to extrapolate the values of the kinetics coefficients of a structure to another with a different temperature. Due to the great thermal inertia of massive structures, such as dams, large temperature variations rarely occur. For this reason, it is considered that the whole structure maintains

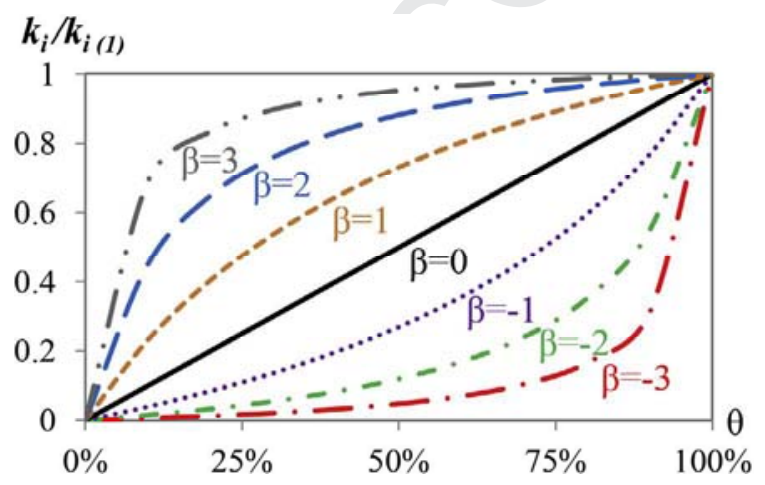

Fig. 2. Variation of the kinetic coefficient of the reactions with the water content of the concrete.

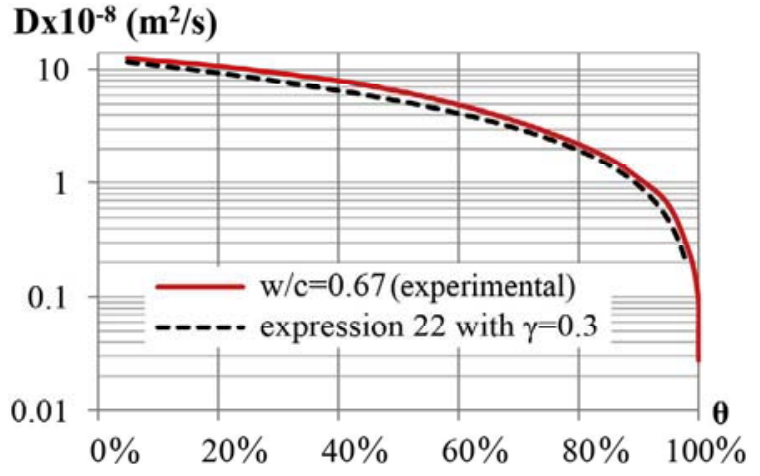

Fig. 3. Variation of the diffusion coefficient of oxygen as a function of the water content: experimental [44] value and that obtained by expression (22).

an average temperature, whose effect is taken into account indirectly by the adopted value of $k_{i(1)}$ in Eq. (21).

\section{Determination of the main parameters of the model}

- Amount of pyrrhotite: The pyrrhotite content in the aggregate can be estimated, for example, using the percentage of sulfates obtained from a chemical analysis (using X-ray fluorescence methods). In the case of the dams analyzed in this study, the aggregates used presented an $\mathrm{SO}_{3}$ content of $1.98 \%$ [40], which corresponds to about 375 moles of pyrrhotite $/ \mathrm{m}^{3}$ of concrete, taking into account the dosage of such concretes, the molar mass of the $\mathrm{SO}_{3}$ and the $\mathrm{S}$. The analytical process to estimate the amount of pyrrhotite is presented in more detail in [46].

- Oxygen concentration: The oxygen concentration in concrete surfaces exposed to air will be considered to be equal to the atmospheric oxygen concentration $\left(9.26 \mathrm{~mol} / \mathrm{m}^{3}\right)$. Moreover, it seems reasonable to think that the initial concentration of oxygen inside the concrete of the dam is not zero, but a reduced value, well below the atmospheric concentration. Due to the low initial content of oxygen, when compared with the initial content of pyrrhotite, the initial oxygen content in the concrete will be quickly consumed, without oxidizing a significant amount of pyrrhotite, but leaving a small amount of iron ions $\left(\mathrm{Fe}^{2+}, \mathrm{Fe}^{3+}\right)$, presenting a low influence on the kinetics of the process. In the simulations presented in this study, a reduced initial concentration of oxygen has been considered.

- Initial concentration of $\mathrm{Fe}^{2+}$ : As explained in Section 3.1, the cycle between reactions (2) and (4) requires an initial content of $\mathrm{Fe}^{2+}$ or $\mathrm{Fe}^{3+}$ to start. An initial content of $\mathrm{Fe}^{2+}$ has been adopted for the model, which can result from the oxidation initiated by oxygen in reaction (1). This parameter is involved in the study of $\mathrm{Fe}^{3+}$ oxidation. Because of this, a low content of $\mathrm{Fe}^{2+}$ is estimated $\left(<10 \mathrm{~mol} / \mathrm{m}^{3}\right)$ so that most of the iron sulfide oxidation occurs through reactions (2) and (4).

- Oxygen diffusion coefficient: The oxygen diffusion coefficient in the concrete is quite variable depending on the porosity and water content of the material. In the literature, for an average water content of $80 \%$, the values of this coefficient range from $10^{-8}$ to $10^{-9} \mathrm{~m}^{2} / \mathrm{s}$ for a conventional concrete [43-45]. The dependence of the porosity of the material is indirectly considered in the model by the assumed values of the diffusion coefficient in a dry concrete $\left(D_{(0)}\right.$ in Eq. (22)). For a dam concrete, the $D_{(0)}$ values in the range of $1 \cdot 10^{-7}$ to $5 \cdot 10^{-7} \mathrm{~m}^{2} / \mathrm{s}$ were adopted with $\gamma=0.3$ to determine these coefficients as a function of the water content. 
- Kinetic coefficient $k_{5}$ : This coefficient was estimated in $k_{5}=3.64 \cdot 10^{-9} \mathrm{~m}^{3} /(\mathrm{mol} \mathrm{s})$ by inverse analysis of the experimental data obtained by Gomides [38], who tested concretes under the ISA, where, as discussed in the next section, the oxidation occurred with oxygen as the main oxidant.

- Kinetic coefficients $k_{2}$ and $k_{4}$ : These coefficients were estimated in $k_{2}=1.58 \cdot 10^{-7}$ and $k_{4}=2.85 \cdot 10^{-11} \mathrm{~m}^{3} /(\mathrm{mol} \mathrm{s})$, in accordance with the analysis presented in Section 10. A parametric study of the influence of the kinetic coefficients $k_{2}$ and $k_{4}$ may be found in [46]. In this study was found that the variation of more or less five times in these coefficients affects the speed of the process, but does not change the shape of the evolution in time of the phenomenon (the " $S$ " shape curve).

\section{Initial results and discussion}

The developed kinetic model was applied in the following cases: first to a material point and then to a generic unidirectional case. Table 2 presents the parameters adopted for the simulations.

The proposed model does not consider the change in $\mathrm{pH}$ during the oxidation process. As a result, oxidation will be studied separately, first considering an alkaline $\mathrm{pH}$ (with $\mathrm{O}_{2}$ as oxidant) and then in a very acidic $\mathrm{pH}$ (with $\mathrm{Fe}^{3+}$ as oxidant).

Fig. 4 shows the kinetics of oxidation for the two oxidants in a single point under a constant concentration of oxygen (equal to the atmospheric concentration) and saturation of water $(\theta=100 \%)$ as a function of time in relative values. It can be observed that oxidation by oxygen results in an exponential evolution over time. The ISA begins immediately, reducing its speed with the reduction of the iron sulfide concentration until the end of the process. Moreover, oxidation by $\mathrm{Fe}^{3+}$ have an evolution in time of ISA with an " $S$ " shape. The oxidation starts very slow due to the low concentration of the reactants in reaction (2) (which converts $\mathrm{Fe}^{2+}$ to $\mathrm{Fe}^{3+}$ ). Then, with the increasing iron ions concentration, the rate of the process increases until an inflexion point, from the oxidation rate starts to decrease with the reduction of the iron sulfide concentration until the end of the process.

Now, a unidirectional concrete section is analyzed, with a point representing the concrete surface exposed to air $(\lambda=0)$, and as a function of the distance to it (or penetration, $\lambda$ ), the evolution of the ISA over time is determined. To take into account the effect of the water content variation on the section, a simplification is adopted, which is suitable for the case of concrete dams, and consists of assuming that almost all concrete is saturated due the continuous contact with the water in the reservoir, except for the area near the downstream face, where the water content decreases to the atmospheric moisture. The following expression is proposed to obtain the water content as a function of the distance of the point to the surface exposed to air (the seasonal variation of the water content is not considered).

$\theta_{(\lambda)}=\theta_{(0)}+\left(1-\theta_{(0)}\right)\left(1-e^{-\alpha \lambda}\right)$

where $\theta_{(0)}$ is the water content of the concrete surface exposed to air, $\lambda$ is the distance from the point to this surface, and $\alpha$ is a parameter that controls the shape of the water content variation $(\theta)$ with $\lambda$.

Fig. 5 shows the results of expression (23) for different values of $\alpha$. It can be seen that $\alpha=0$ gives a constant value of $\theta$ in the section, and as its value increases, the size of the partially saturated zone of concrete is reduced.

The following considerations were adopted for the analysis:

- The numerical solution is obtained with the system of equations composed of expressions (7) and (8) (with $\mathrm{O}_{2}$ as oxidant) or (9)(12) (with $\mathrm{Fe}^{3+}$ as oxidant).

Table 2

Parameters adopted for the simulations to a material point and to a generic unidirectional case.

\begin{tabular}{lll}
\hline Parameter & Unit & Value \\
\hline$\left[\mathrm{O}_{2}\right]_{\text {atm }}$ & $\mathrm{mol} / \mathrm{m}^{3}$ & 9.26 \\
{$\left[\mathrm{Fe}_{1-x} \mathrm{~S}\right]_{0}$} & $\mathrm{~mol} / \mathrm{m}^{3}$ & 375.00 \\
{$\left[\mathrm{Fe}^{2+}\right]_{0}$} & $\mathrm{~mol} / \mathrm{m}^{3}$ & 10.00 \\
$k_{2}$ & $\mathrm{~m}^{3} /(\mathrm{mol} \mathrm{s})$ & $1.58 \cdot 10^{-7}$ \\
$k_{4}$ & $\mathrm{~m}^{3} /(\mathrm{mol} \mathrm{s})$ & $2.85 \cdot 10^{-11}$ \\
$k_{5}$ & $\mathrm{~m}^{3} /(\mathrm{mol} \mathrm{s})$ & $3.64 \cdot 10^{-9}$ \\
$D_{(0)}$ & $\mathrm{m}^{2} / \mathrm{s}$ & $10^{-7}$ \\
$\theta_{(0)}$ & $\%$ & 75 \\
$\alpha$ & - & 0.5 \\
$\beta$ & - & -1.5 \\
$\gamma$ & - & 0.3 \\
\hline
\end{tabular}

\section{ISA progress}

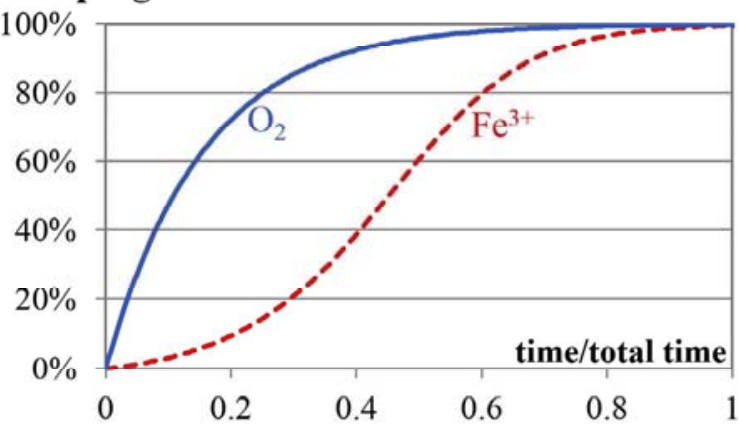

Fig. 4. ISA kinetics for the cases with $\mathrm{O}_{2}$ and $\mathrm{Fe}^{3+}$ as oxidizers.

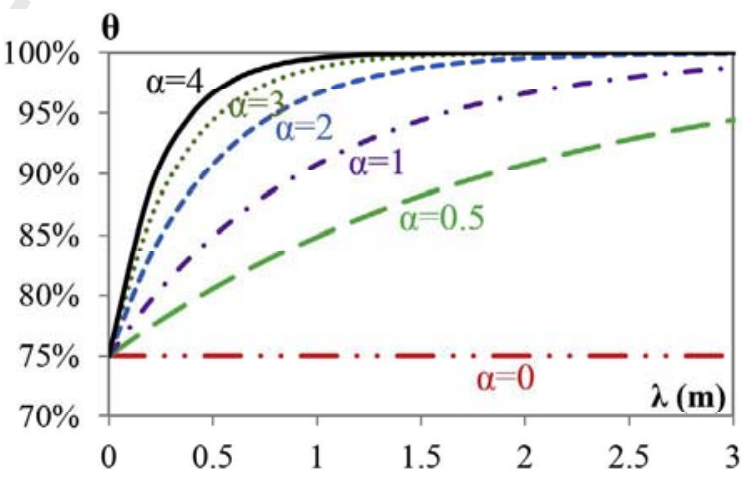

Fig. 5. Water content variation with the distance from the surface exposed to air.

- The oxygen concentration in concrete surfaces exposed to air (nodes with penetration $\lambda=0$ ) was considered to be equal to the atmospheric oxygen concentration $\left(9.26 \mathrm{~mol} / \mathrm{m}^{3}\right)$.

- To solve the global process (diffusion problem expressed by the Eqs. (7) or (9)), the finite differences method was used (with a discretization in space and time small enough to the goodness of the results).

- To solve the local process (chemical reactions at each node of the section, expressed by Eqs. (8) or (10)-(12)), an incremental and iterative process was used (Newton method).

- The calculations were made iteratively until the results of the global process (oxygen diffusion) and the local process (chemical reactions) had converged.

Figs. 6 and 7 show the ISA progress in a unidirectional section with oxygen and $\mathrm{Fe}^{3+}$ as oxidizer, respectively. In these figures, it can be noted that the chemical reactions are localized in a small area near the oxygen source $(\lambda=0)$, reaching approximately 


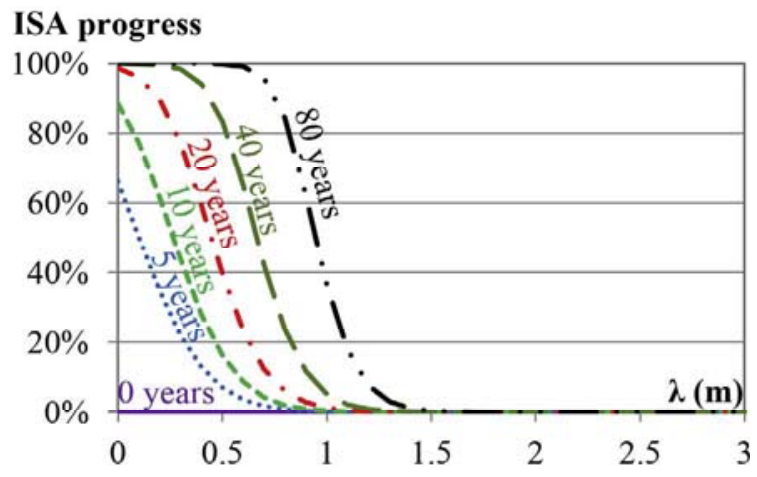

Fig. 6. ISA progress as a function of $\lambda$ with oxygen as oxidizer.

$1.0 \mathrm{~m}$ in the 80 years of simulation. These curves are correlated in proportion with the distribution of the generated deformations, as expressed in Eq. (16).

It can also be observed in these figures that the oxidation with oxygen begins quickly (as shown in Fig. 6 , when the area near $\lambda=0$ has reached $60 \%$ at year 5), while that with $\mathrm{Fe}^{3+}$ begins slowly, with an initial period of approximately 10 years during which there is no significant evolution of the ISA (as shown in Fig. 7, where no point of the section has exceeded the $12 \%$ until year 10 ).

A different way of representing this phenomenon is by using kinetic curves at different distances (penetrations, $\lambda$ ), as shown in Figs. 8 and 9 for the cases with oxygen and $\mathrm{Fe}^{3+}$ as oxidizers, respectively. In both the figures, it can be seen that the rate of the process decreases with the increase in the oxygen source distance. This happens because the process is more governed by oxygen diffusion than by the reaction speed (the influence of which

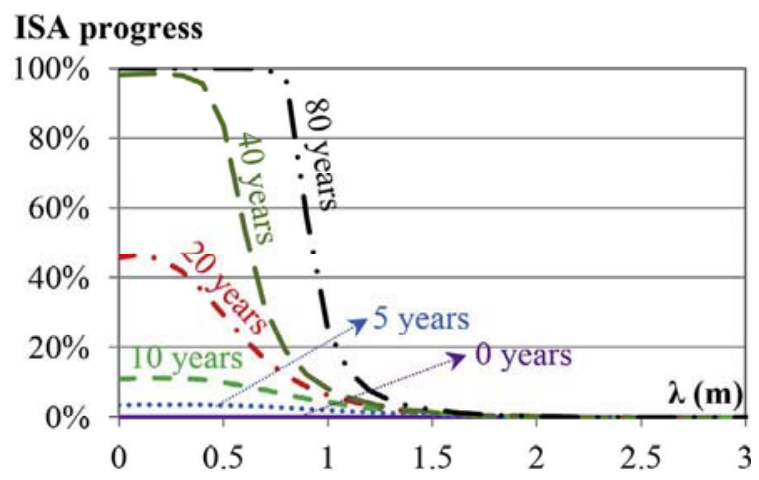

Fig. 7. ISA progress as a function of $\lambda$ with $\mathrm{Fe}^{3+}$ as oxidizer.

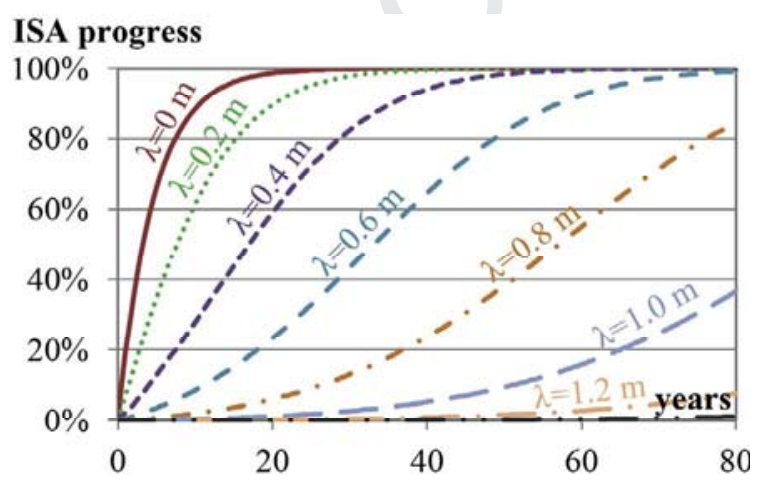

Fig. 8. ISA progress as a function of time for different penetrations $(\lambda)$ with oxygen as oxidizer.

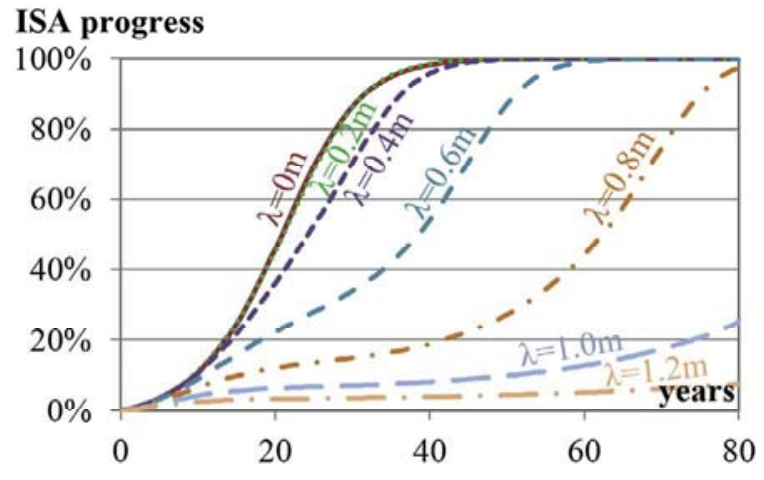

Fig. 9. ISA progress as a function of time for different penetrations $(\lambda)$ with $\mathrm{Fe}^{3+}$ as oxidizer.

can be seen in the left-most curve corresponding to a point on the surface in contact with air, $\lambda=0$ ). In Fig. 9, the activation period of about 10 years in oxidation by $\mathrm{Fe}^{3+}$ can be seen.

In structures affected by the ISA, it is reasonable to presume that during oxidation by oxygen, non-recoverable displacements could be present at early periods, while during oxidation by $\mathrm{Fe}^{3+}$, these displacements could appear years after the end of construction of the structure.

In dams affected by the ISA, the evolution of the movements usually has an activation time of about 10 years or more; hence, it is reasonable to assume that in the case of concrete dams, the main oxidant is $\mathrm{Fe}^{3+}$. In laboratory tests conducted by Gomides [38] in concrete specimens $(7.5 \times 7.5 \times 28.5 \mathrm{~cm})$ with aggregates containing pyrrhotite, the evolution of axial deformation over time (presented in Fig. 10) was consistent with that observed in oxidation by oxygen with an exponential evolution over time.

From the analysis of these two cases, namely dams (indicating $\mathrm{Fe}^{3+}$ as the main oxidant) and laboratory (indicating oxygen as the main oxidant), the question of why the difference between these two cases occur raises. One possible explanation is related to the size of the aggregate used. While in the laboratory, a conventional concrete with a maximum aggregate size of $19 \mathrm{~mm}$ is used, in the concrete dams, large aggregates are often used with maximum diameters of $125 \mathrm{~mm}$ or more.

The difference in the aggregates size influences the way in which the $\mathrm{pH}$ of the cement paste affects the $\mathrm{pH}$ of the interior of the aggregates. The diffusion of alkalis from the paste to the interior of the aggregates will be faster in small aggregates (due to which the small aggregates have higher relation surface volume and lower transport distances from the alkalis). This implies that in a small aggregate, although oxidation tends to lower the $\mathrm{pH}$ inside

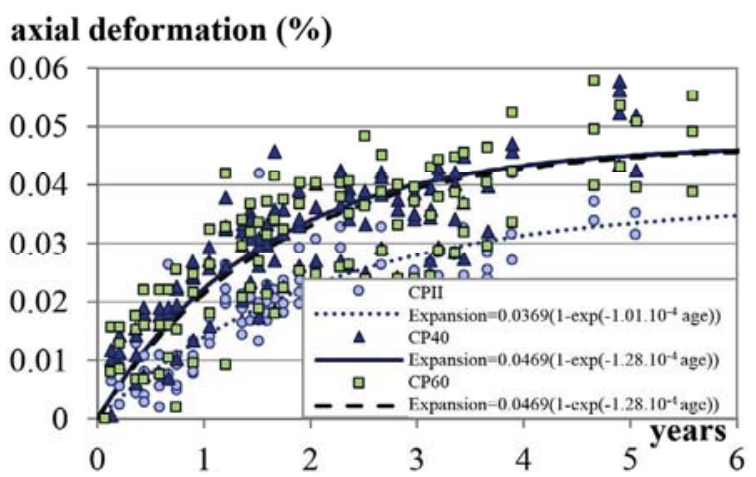

Fig. 10. Axial deformation over time measured in concrete specimens under the ISA [38]. 
the aggregate, the diffusion of alkalis from the paste will be sufficient to maintain the $\mathrm{pH}$ alkaline (condition where oxygen is the main oxidant). In turn, in large aggregates, the entry of alkalis from the paste may not be sufficient to counteract the reduction in $\mathrm{pH}$ caused by the oxidation of pyrrhotite, creating a condition where $\mathrm{Fe}^{3+}$ is the main oxidant.

\section{Application to two real dams}

The diffusion-reaction model was applied to the cases of two real dams, Graus and Tavàscan, which present high nonrecoverable horizontal displacements due to the ISA $[40,46]$. Both the dams have a monitoring system on the crest, installed in Tavàscan since its entry into service and in Graus 10 years after that.

The following considerations were adopted for the numerical analysis:

- A 2D discretization in finite elements of block 5 for Graus dam and block 2 for Tavàscan dam was used.

- Calculations were performed in plane strain condition, assuming a linear-elastic behavior for the materials (Young's modulus of $20 \mathrm{GPa}$ and Poisson's ratio of 0.2 ). This simplification was made to demonstrate the applicability of the model, but obviously did not take into account the nonlinear effects (such as damage, creep, among others), whose study is not part of this paper. It should be emphasized that the elastic simulation underestimates the displacements, which leads to overvalue

Table 3

Parameters adopted in the simulation of the dams.

\begin{tabular}{llll}
\hline Parameter & Unit & Graus & Tavàscan \\
\hline$\left[\mathrm{O}_{2}\right]_{\mathrm{atm}}$ & $\mathrm{mol} / \mathrm{m}^{3}$ & 9.26 & 9.26 \\
{$\left[\mathrm{Fe}_{1-x} \mathrm{~S}\right]_{0}$} & $\mathrm{~mol} / \mathrm{m}^{3}$ & 375.00 & 375.00 \\
{$\left[\mathrm{Fe}^{2+}\right]_{0}$} & $\mathrm{~mol} / \mathrm{m}^{3}$ & 2.00 & 5.00 \\
$k_{2}$ & $\mathrm{~m}^{3} /(\mathrm{mol} \mathrm{s})$ & $1.58 \cdot 10^{-7}$ & $1.58 \cdot 10^{-7}$ \\
$k_{4}$ & $\mathrm{~m}^{3} /(\mathrm{mol} \mathrm{s})$ & $2.85 \cdot 10^{-11}$ & $2.85 \cdot 10^{-11}$ \\
$D_{(0)}$ & $\mathrm{m}^{2} / \mathrm{s}$ & $5 \cdot 10^{-7}$ & $5 \cdot 10^{-7}$ \\
$\theta_{(0)}$ & $\%$ & $85 \%$ & $85 \%$ \\
$\alpha$ & - & 0.5 & 0.5 \\
$\beta$ & - & -1.4 & -1.4 \\
$\gamma$ & - & 0.3 & 0.3 \\
$f$ & - & 0.32 & 0.45 \\
$\phi$ & $\%$ & 10 & 10 \\
$(\Delta V / V)_{\text {total }}$ & - & 0.05 & 0.05 \\
$(\Delta V / V)_{\infty}$ & - & 0.018 & 0.005 \\
\hline
\end{tabular}

the imposed deformations needed to reproduce the measured displacements. A complete nonlinear study of the Graus dam is subject of another study that could be found in [42].

- As simplification, the water content distribution in the interior of the dam is defined by expression (23). The volumetric deformation in each point of the finite element mesh was obtained from the distance $(\lambda)$ of the mesh point to the nearest surface exposed to air (oxygen source, as the downstream face) using the unidirectional solution presented in the previous section.

- It is considered that the oxidation of pyrrhotite occurs with $\mathrm{Fe}^{3+}$ as the main oxidant.

- It is considered that an isotropic distribution of the volumetric expansion, obtained with expression (20), applied to each node of the mesh as imposed deformation as in the temperature's case.

Both the dams dating from the late 1960s and early 1970s, were built relatively close to each other in the Catalan Pyrenees (resulting in similar environmental conditions such as temperature and humidity), with cement and aggregates very similar. Because of this, the water content at the surface of the concrete $\left(\theta_{(0)}\right)$, the porosity $(\phi)$, the initial concentration of pyrrhotite $\left(\left[\mathrm{Fe}_{1-x} S\right]_{0}\right)$, as well as several other parameters were estimated with similar or equal values for both the dams. The $(\Delta V / V)_{\text {total }}$ was estimated using expression (17), by assuming that all pyrrhotite had reacted, and the sulfate attack occurred only by reaction (15) (reaction of gypsum with monosulfoaluminate).

Due to the scarce literature available for the estimation of some parameters of the model, these were obtained by inverse analysis to fit the evolution of the displacements measured in these structures over time. This analysis resulted in a small initial content of $\mathrm{Fe}^{2+}$, as predicted in Section 9, and equal kinetic coefficients for reactions (2) and (4) in both the dams. The capillary porosity fraction $(f)$ was estimated to obtain values of deformations that generate displacements on the structures similar to the measured ones. This resulted in different values for both the dams, but within the range reported in the literature [41]. Table 3 presents all the parameters used in the simulations.

Figs. 11 and 12 show the view of the dams together with the discretized cross-section, which present a color diagram of the ISA progress at 40 years of simulation. It can be observed that the ISA is located in a zone near the downstream face (near the oxygen source). The expansion of the concrete in this area tends to generate horizontal displacements on the crest toward upstream.
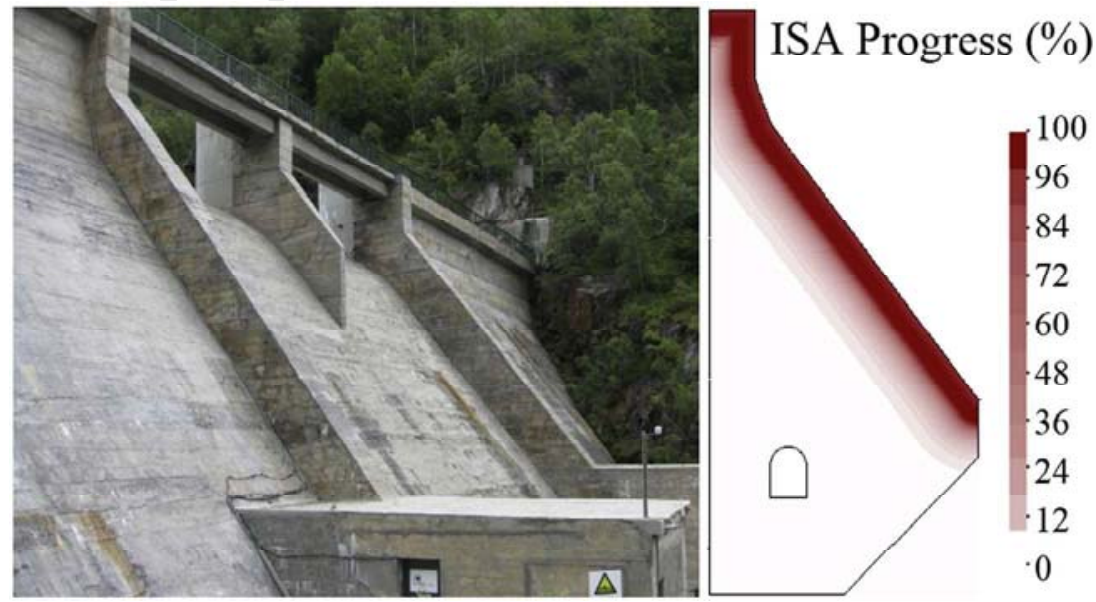

Fig. 11. View of Graus dam and ISA progress in the cross-section of block 5 at 40 years of the numerical simulation. 

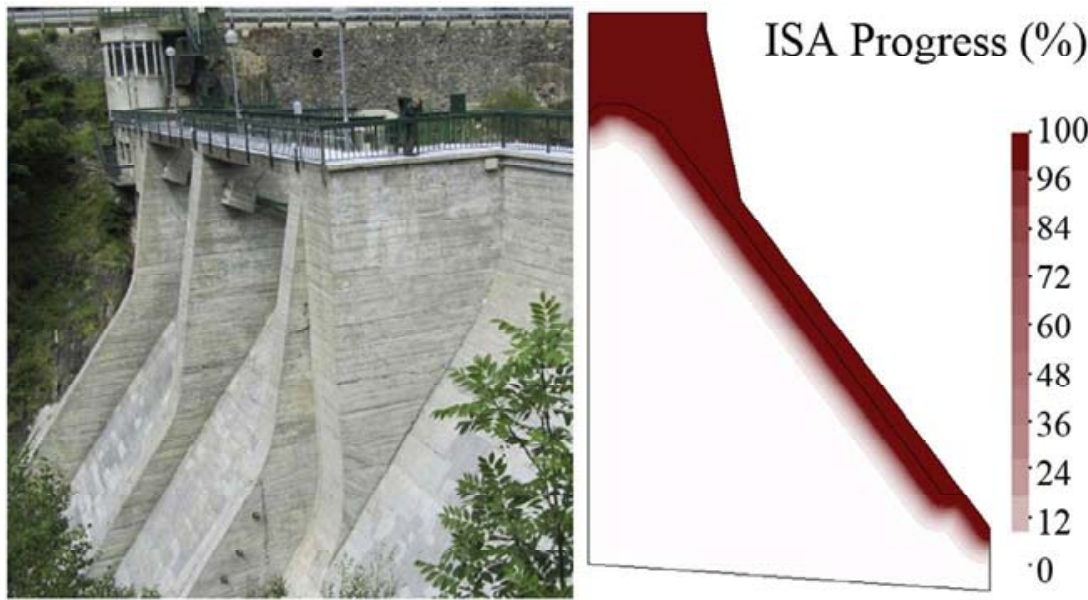

Fig. 12. View of Tavàscan dam and ISA progress in the cross-section of block 2 at 40 years of the numerical simulation.

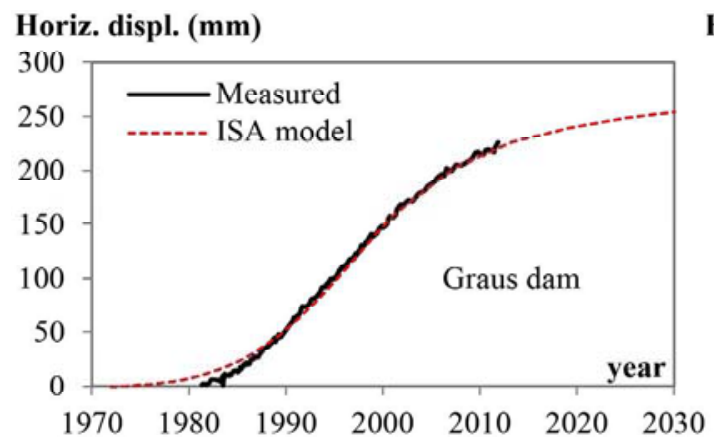

Horiz. displ. (mm)

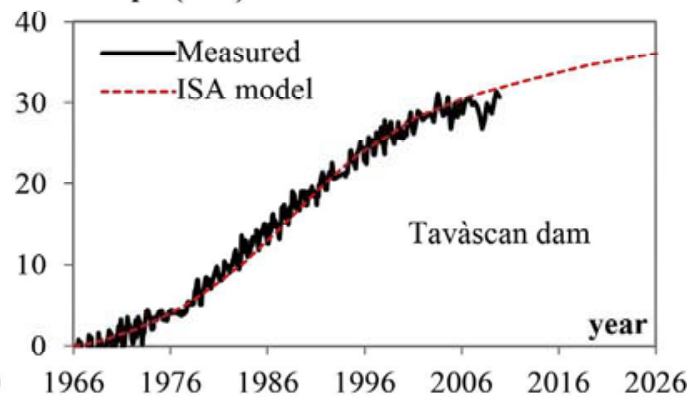

Fig. 13. Horizontal displacements measured and calculated on the crest of Graus and Tavàscan dams over time.

Fig. 13 shows the measured and calculated horizontal displacements on the crest of Graus and Tavàscan dams. The good agreement between the measured displacements and those obtained with the model in both the dams could be observed in the figure.

Due to lack of experimental data, it was not possible to obtain accurate values of the kinetic coefficients of the reactions (2) and (4). For this reason, they were obtained in order to fit the time evolution of the displacements measured in the dams. Due to the similar environmental conditions in both structures, the values of these coefficients may be directly compared. It may be seen in Table 3 and Fig. 13 that the same values of $k_{2}$ and $k_{4}$ allow to obtain the evolution in time of the displacements in both dams. These shows the predictive power of the model, since the coefficients obtained with one dam may be used to predict the behavior of the other dam.

\section{Conclusions}

A kinetic model of ISA evolution over time was proposed and developed in this study using a diffusion-reaction model that considers the oxygen transport into the concrete and its consumption by the oxidation reactions. This allows determining the distribution and evolution of the volumetric deformations due to the ISA over time.

The importance of oxygen diffusion process in the oxidation, which limited the area in which the ISA developed (near surfaces exposed to air, which are the main oxygen sources) has been clearly demonstrated. The influence of several parameters has been taken into account in the process, highlighting the importance of water content, which affects the reactions kinetics and the oxygen transport.

The differences in the kinetic curves obtained with the oxidation by oxygen and $\mathrm{Fe}^{3+}$ indicates that, in the case of concrete dams, $\mathrm{Fe}^{3+}$ is the main oxidant, whose kinetics is characterized by an " $\mathrm{S}$ " shape, similar to that observed in dams affected by the ISA. Meanwhile, in a conventional concrete, experimental results indicate that oxygen is the main oxidant, whose kinetics is characterized by an exponential evolution over time. The difference between them would be conditioned by the aggregate size used on these concretes. The $\mathrm{pH}$ of the large aggregates was not as much influenced by the $\mathrm{pH}$ of the cement paste as the small aggregates. It follows that even with the tendency of pyrrhotite oxidation to reduce the $\mathrm{pH}$, in the small aggregates, the $\mathrm{pH}$ is kept more alkaline due to the greater influence of the $\mathrm{pH}$ of the cement paste, while the large aggregates can present an acidic $\mathrm{pH}$. The value of the $\mathrm{pH}$ inside the aggregates determines the main oxidant of the pyrrhotite (oxygen: $\mathrm{pH}>4$ and $\mathrm{Fe}^{3+}: \mathrm{pH}<4$ ).

The proposed model was applied in two real dams. Although the results are qualitative (due to non-consideration of nonlinear effects, which leads to an overvaluation of the imposed deformations), it was possible to appreciate the potential of the model, which could predict the evolution over time, and distribution of the deformations on the structure due to the ISA.

\section{Acknowledgments}

The authors acknowledge the funding from the Ministerio de Economía y Competitividad (MEC) de España for the project BIA2013-49106-C02-1-R and the second author for the project 
BIA2012-36898 funded by MEC (Madrid), which includes FEDER funds. The funding and support provided by the Research Contract UPC-ENDESA are also acknowledged. The first author thanks the scholarship FPU (MEC)

\section{References}

[1] T. Schmidt, A. Leemann, E. Gallucci, K. Scrivener, Physical and microstructura aspects of iron sulfide degradation in concrete, Cem. Concr. Res. 41 (3) (2011) 263-269, http://dx.doi.org/10.1016/j.cemconres.2010.11.011.

[2] A. Rodrigues, J. Duchesne, B. Fournier, B. Diurand, P. Rivard, M. Shehata Mineralogical and chemical assessment of concrete damaged by the oxidation of sulfide-bearing aggregates: importance of thaumasite formation on reaction mechanisms, Cem. Concr. Res. 42 (10) (2012) 1336-1347, http://dx.doi.org/ 10.1016/j.cemconres.2012.06.008

[3] I. Casanova, L. Agulló, A. Aguado, Aggregate expansivity due to sulfide oxidation - I. Reaction system and rate model, Cem. Concr. Res. 26 (1996) 993-998, http://dx.doi.org/10.1016/0008-8846(96)00085-3.

[4] I. Casanova, L. Agulló, A. Aguado, Aggregate expansivity due to sulfide oxidation - II. Physico chemical modeling of sulphate attack, Cem. Concr. Res. 27 (1997) 1627-1632, http://dx.doi.org/10.1016/0008-8846(96)00085-3.

[5] I. Fernandes, M. Pericão, P. Hagelia, F. Noronha, M.A. Ribeiro, J. Maia Identification of acid attack on concrete of a sewage system. Mater. Struct. Mater. Constr. 45 (3) (2012) 337-350, http://dx.doi.org/10.1617/s11527-0119769-y.

[6] Y. Wakizaka, K. Ichikawa, Y. Kakamura, S. Anan, The formation and role of ettringite in lowa highway concrete deterioration, Cem. Concr. Res. 4 (2003) 1-

[7] J. Espinós, A. Aguado, C. López, A. Campos, S. Chinchón-Payá, Expansion studies for the Paso Nuevo dam, Proceedings of the 2nd International Congress on Dam Maintenance and Rehabilitation, Zaragoza, CRC Press, Taylor and Francis Group, Balkema, 2010, pp. 143-152.

[8] I. Oliveira, S.H. Cavalaro, A. Aguado, New kinetic model to quantify the internal sulfate attack in concrete, Cem. Concr. Res. 43 (2013) 95-104, http://dx.doi. org/10.1016/j.cemconres.2012.09.010.

[9] I. Oliveira, S.H.P. Cavalaro, A. Aguado, New unreacted-core model for predict pyrrhotite oxidation in concrete dams, J. Mater., Civ. Eng. ASCE 25 (3) (2013) 372-381, http://dx.doi.org/10.1061/(ASCE)MT.1943-5533.0000531.

[10] J.S. Chinchon, C. Ayora, A. Aguado, F. Guirado, Influence of weathering of iron sulphides contained in aggregates on concrete durability, Cem. Concr. Res. 25 (5) (1995) 1264-1272, http://dx.doi.org/10.1016/0008-8846(95)00119-W.

[11] C. Ayora, S. Chinchón, A. Aguado, F. Guirado, Weathering of iron sulfides and concrete alteration: thermodynamic model and observation in dams from Central Pyrenees, Cem. Concr. Res. 28 (1998) 1223-1235, http://dx.doi.org/ 10.1016/S0008-8846(98)00137-9.

[12] A. Neville, The confused world of sulfate attack on concrete, Cem. Concr. Res. 34 (2004) 1275-1296, http://dx.doi.org/10.1016/j.cemconres.2004.04.004.

[13] S. Chinchon-Payá, A. Aguado, A. Chinchon-Yepes, A comparative investigation of the degradation of pyrite and pyrrhotite under simulated laboratory conditions, Eng. Geol. 127 (2012) 75-80, http://dx.doi.org/10.1016/j. enggeo.2011.12.003.

[14] A.M. Neville, Properties of Concrete, Longman Group UK Limited, 2002

[15] J. Skalny, J. Marchand, I. Odler, Sulfate Attack on Concrete, tenth ed., Spon Press, London, 2002.

[16] P.K. Mehta, P.J.M. Monteiro, Concrete Microstructure, Properties, and Materials, third ed., McGraw-Hill, New York, 2006.

[17] A.M. Soares, M. Viana, N.L.A. Corrêa, S.F. Corrêa, M.F. Corrêa, F.R. Andriolo, Rio Descoberto Dam: water supply system for Brasília city - Brazil - rehabilitation and performance, in: Proceeding ICOLD 21st Congress on Large Dams, Montreal, 2003.

[18] W. Puatatsananon, V. Saouma, Chemo-mechanical micromodel for alkali-silica reaction, ACI Mater. J. 110 (2013) 67-77.

[19] S. Multon, A. Sellier, M. Cyr, Chemo-mechanical modeling for prediction of alkali silica reaction (ASR) expansion, Cem. Concr. Res. 39 (2009) 490-500 http://dx.doi.org/10.1016/j.cemconres.2009.03.007.

[20] A.E Idiart C.M. López, I. Carol, Chemo-mechanical analysis of concrete cracking and degradation due to external sulfate attack: a meso-scale model, Cem. Concr. Compos. 33 (2011) 411-423, http://dx.doi.org/10.1016/j. cemconcomp.2010.12.001.
[21] R. Tixier, B. Mobasher, Modeling of damage in cement-based materials subjected to external sulfate attack. I: Formulation, J. Mater. Civ. Eng. 15 (2003) 305-313.

[22] T. Ikumi, I. Segura, S.H.P. Cavalaro, A. Aguado, External sulfate attack: porosimetry and damage based mode, Cem. Concr. Res. 63 (8) (2014) 105 116, http://dx.doi.org/10.1016/j.cemconres.2014.05.011.

[23] X.-B. Zuo, W. Sun, C. Yu, Numerical investigation on expansive volume strain in concrete subjected to sulfate attack, Constr. Build. Mater. 36 (2012) 404-410, http://dx.doi.org/10.1016/j.conbuildmat.2012.05.020.

[24] S. Chao, C. Jiankang, Z. Jue, Z. Minghua, Y. Jian, A new diffusion model of sulfate ions in concrete, Constr. Build. Mater. 39 (2013) 39-45, http://dx.doi.org/ 10.1016/j.conbuildmat.2012.05.022.

[25] N. Qingke, Z. Changjun, H. Li, X. Shu, H. Gong, B. Huang, Numerical simulation of fly ash concrete under sulfate attack, Constr. Build. Mater. 84 (2015) 261 268, http://dx.doi.org/10.1016/j.conbuildmat.2015.02.088

[26] R. Cerny, P. Rovnaníková, Transport Processes in Concrete, Spon Press, London, 2002.

[27] J. Crank, The Mathematics of Diffusion, Oxford Science Publications, New York, 1979.

[28] M.T. Liang, S.M. Lin, Mathematical modeling and applications, J. Mar. Sci. Technol. 11 (2003) 20-33.

[29] D. Park, Carbonation of concrete in relation to $\mathrm{CO}_{2}$ permeability, Constr. Build Mater. 22 (2008) 2260-2268, http://dx.doi.org/10.1016/j.conbuildmat.2007. 07.032 .

[30] A. Suwito, W. Jin, Y. Xi, C. Meyer, A mathematical model for the pessimum size effect os ASR in concrete, J. Concr. Sci. Eng 4 (2002) 23-24. ISSN: 1295-2826.

[31] E. Samson, J. Marchand, J. Beaudoin, Modeling the influence of chemical reactions on the mechanisms of ionic transport in porous materials. An overview, Cem. Concr. Res. 30 (2000) 1895-1902, http://dx.doi.org/10.1016/ S0008-8846(00)00458-0.

[32] E. Samson, J. Marchand, Modeling the transport of ions in unsaturated cementbased materials, Comput. Struct. 85 (2007) 1740-1756, http://dx.doi.org/ 10.1016/j.compstruc.2007.04.008.

[33] L. Divet, Les réactions sulfatiques internes au béton, Contribution a l'étude des mécanismes de la formation différée de l'ettringite, Paris, Doctoral thesis, Conservatoire National des Arts et Métiers, 2001 (in French).

[34] P.J. Sullivan, K.J. Reddy, J.L. Yelton, Iron sulfide oxidation and the chemistry of acid generation, Environ. Geol. Water Sci. 11 (1988) 288-295.

[35] N. Belzile, Y. Chen, M. Cai, Y. Li, A review on pyrrhotite oxidation, J. Geochem Explor. 84 (2004) 65-76, http://dx.doi.org/10.1016/j.gexplo.2004.03.003.

[36] G. Sposito, Chemical Equilibria and Kinetics in Soils, Oxford University Press, 1994.

[37] J.M. Martínez, A. Aguado, L. Agulló, E. Vázquez, Diagnosis of the behaviour of the Graus and Tabescan dams, in: Proceedings of the Seventeenth International Congress on Large Dams, Vienna 1991.

[38] M.d.J. Gomides, Investigação de agregados contendo sulfetos e seus efeitos sobre a durabilidade do concreto, Porto Alegre: Tesis doctoral, Universidade Federal do Rio Grande do Sul, 2009 (in Portuguese).

[39] J.R. Clifton, J.M. Pommersheim, Sulfate attack of cementitious materials: volumetric relations and expansions, NISTIR 5390, NIST, 1994.

[40] A. Aguado, L. Agulló, I. Casanova, C.M. Lopez, Estudio de fenómenos expansivo en presas de hormigón. De la micro a la macro estructura, Spanish Committee of ICOLD, José Torán Award, 1998 (in Spanish).

[41] R. Tixier, B. Mobasher, Modeling of damage in cement-based materials subjected to external sulfate attack. II: Comparison with experiments, J. Mater. Civ. Eng. 15 (2003) 314-322, http://dx.doi.org/10.1061/(ASCE)08991561(2003) 15:4(314).

[42] H.J.H. Brouwers, Composición de la pasta de cemento portland (parte I), Cemento Hormigón 905 (2007) 6-42. ISSN 0008-8919 (in Spanish).

[43] V.G. Papadakis, C.G. Vayenas, M.N. Fardis, Physical and chemical characteristics affecting the durability of concrete, ACI Mater. J. 88 (1991) 186-196.

[44] A. Bentur, S. Diamond, N.S. Berke, Steel Corrosion in Concrete, third ed., Taylor \& Francis, 1997.

[45] K. Takewaka, T. Yamaguchi, S. Maeda, Simulation model for deterioration of concrete structures due chloride attack, J. Adv. Concr. Technol. 1 (2003) 139146.

[46] A. Campos, Análisis numérico de presas de hormigón bajo acciones expansivas, Barcelona, PhD Tesis, UPC-BarcelonaTech, 2012 (in Spanish). 